\title{
Concrete Slabs' Initial Cracks Assessment using Ground Penetrating Radar
}

\author{
Abdul Razzak T. Ziboon, Nisreen S. Mohammed and Anaam G. Hamad* \\ Building and Construction Engineering Department, University of Technology, Baghdad, Iraq \\ Received 01 Feb 2018, Accepted 05 April 2018, Available online 10 April 2018, Vol.8, No.2 (March/April 2018)
}

\begin{abstract}
Ground-Penetrating Radar (GPR) is extensively used by a multiple group of service providers that incorporate agronomist, archaeologists, criminologists, engineers, environmental specialists, foresters, geologists, geophysicists, hydrologists, land use managers, and soil scientists. In engineering applications include Non-Destructive Testing (NDT) of structures and pavements and locating buried structures etc. GPR is a relatively new geophysical tool that has become increasingly popular due to its high resolution and the need to better understand near-surface conditions. In this paper GPR is applied to six concrete slabs. Radar measurements were performed using a $1000 \mathrm{MHz}$ RAMAC GPR CU-II. Two concrete slabs weren't reinforced, two have simple reinforcement, and the last two have artificial gaps in their reinforcement. Tests were taken after applying $40 \%$ of the slabs' failure loads. Experiments resulted that the extent and severity of the fatigue cracking was possible to be monitored. In addition, the technique was assistive in determining the failure caused by loading reflected by radargrams.
\end{abstract}

Keywords: Ground Penetrating Radar, Non-Destructive Testing Method of Concrete, Concrete Features, Microwave, Concrete, Imaging, Geomatics, Geophysics.

\section{Introduction}

Ground Penetrating Radar (is also known as earth sounding radar, ground probing radar, subsurface radar, or georadar) (GPR) is a high-resolution electromagnetic technique used to evaluate the location and depth of buried objects and to investigate the presence and continuity of natural subsurface conditions and features, without drilling, probing, or digging (Daniels, 1996), Thus GPR is used to locate the buried objects such as landmines (Buan, 2002), pipes, cables and reinforcement (Benson et al., 1983), the location of subsurface cavities and fractures in bedrock (Imse et al., 1985), as well as ground water and moisture (Wright et al., 1984), etc. Ground penetrating radar operates by transmitting electromagnetic wave that is radiated from a transmitting antenna down into the ground. The electromagnetic wave is reflected from various buried objects or distinct contacts between different earth materials that have contrasting dielectric properties, such as at the boundary between soil and a landmine or between soil and a large rock. The reflections are created by an abrupt change with the dielectric properties in the ground. These electrical properties are namely, relative permittivity, relative

*Corresponding author Anaam G. Hamad (ORCID ID: 0000-00030495-6280) is M.Sc. in Geomatics Engineering; Dr. Abdul Razzak T. Ziboon is working as Professsor and Dr. Nisreen S. Mohammed as Assistant Professor; DOI: https://doi.org/10.14741/ijcet/v.8.2.22 permeability and conductivity. However, not all three parameters provide useful information to the GPR. In addition, it is important to mention that the effectiveness of GPR survey is a function of site conditions, the equipment used, and experience of personnel using the equipment and reading the results (Cao et al., 2007)

\section{GPR Instrumentation}

Generally, the operation of a commercial GPR system requires two operators, one to drag the antennas along the ground such as vehicle or cart, the other to control the instrument operations from a console which is often a laptop or another electronic module connected to the antennas by cable or optic fiber (Griffin et al., 2002). The type of GPR used in the site work is Sweden type of MALA Geosciences Company. The sketched Figure (1) shows the full system structure for both types of radar networks.

The capability and accuracy of GPR depends on many factors such as antenna frequency and the operating setting parameters including antenna separation, max. time window, time window, EM wave velocity for visualizing depth purposes, and point interval and stacking for the horizontal resolution. The $1000 \mathrm{MHz}$ antenna was previously tested for its operating settings in different work site. Table (1) shows antennas frequency specification advised accordance to MALÅ Geoscience leaders. 


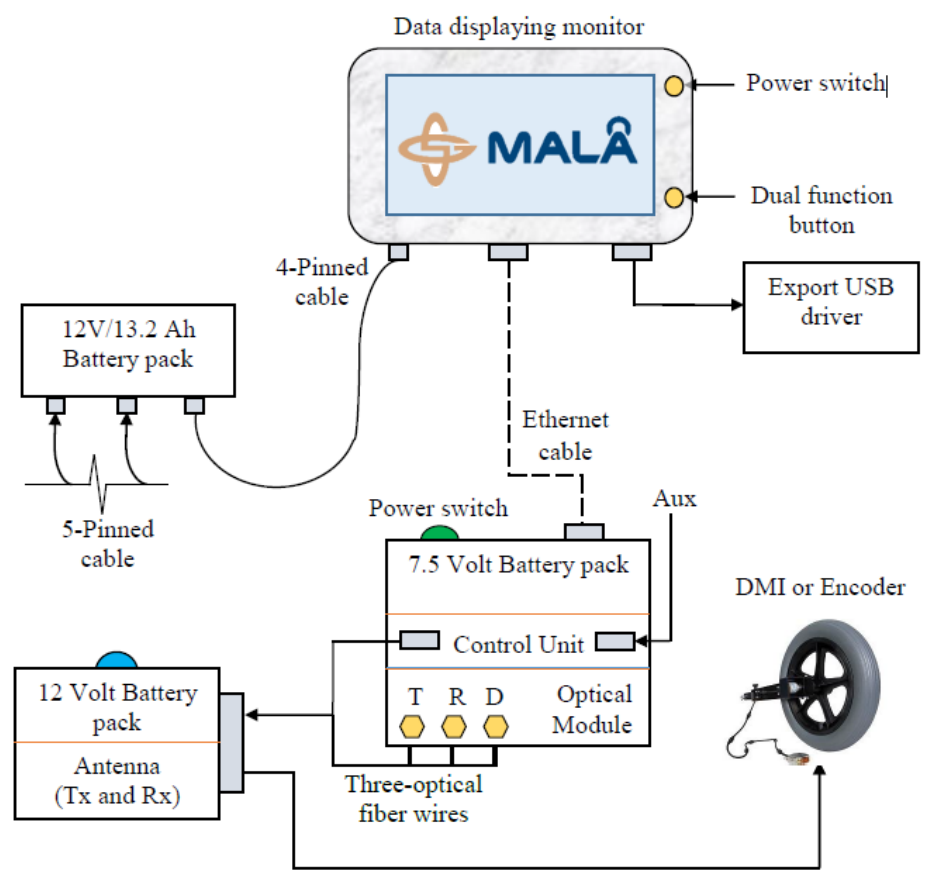

Fig.1 The configuration structure for both GPR systems used

Table 1 Shielded antennas and their suitable areas of application with their approximate depth ranges (MALA Geoscience Manual, 2005)

\begin{tabular}{|c|c|}
\hline $100 \mathrm{MHz}$ & $\begin{array}{l}\text { The shielded } 100 \mathrm{MHz} \text { antenna is the lowest (shielded) antenna frequency commercially available. Gives optimal data in } \\
\text { noisy environments and designed for relatively deep penetration and mid-range resolution. Suitable for geological and } \\
\text { geotechnical applications. Lower limit of object target size is } 0.1-1 \mathrm{~m} \text {. } \\
\text { Approximate depth range is } 2-15 \mathrm{~m} \text {. Approximate max. penetration depth is } 15-25 \mathrm{~m} \text {. }\end{array}$ \\
\hline $250 \mathrm{MHz}$ & $\begin{array}{l}\text { The } 250 \mathrm{MHz} \text { shielded antenna is a general purpose antenna that delivers medium penetration and medium to good } \\
\text { resolution. It is commonly used for utility detection, underground storage tanks and void detection. Lower limit of object } \\
\text { target size is } 0.05-0.5 \mathrm{~m} \text {. Approximate depth range is } 1-10 \mathrm{~m} \text {. } \\
\text { Approximate max. penetration depth is } 5-15 \mathrm{~m} \text {. }\end{array}$ \\
\hline $500 \mathrm{MHz}$ & $\begin{array}{l}\text { The } 500 \mathrm{MHz} \text { shielded antenna is a very popular general purpose antenna that delivers mid-range penetration and good } \\
\text { resolution. Commonly used for utility detection, road surveys and archaeological investigations. Lower limit of object target } \\
\text { size is } 0.04 \mathrm{~m} \text {. Approximate depth range is } 1-5 \mathrm{~m} \text {. Approximate max. } \\
\text { penetration depth is } 3-10 \mathrm{~m} \text {. }\end{array}$ \\
\hline $800 \mathrm{MHz}$ & $\begin{array}{l}\text { The } 800 \mathrm{MHz} \text { antenna delivers very good resolution used for mapping road beds, concrete structures or other shallow } \\
\text { investigations. The interchangeable electronics makes the } 800 \mathrm{MHz} \text { antenna an economically good alternative to the high } \\
\text { resolution } 1 \mathrm{GHz} \text { antenna. Lower limit of object target size is } 0.02 \mathrm{~m} \text {. } \\
\text { Approximate depth range is } 0.4-2 \mathrm{~m} \text {. Approximate max. penetration depth is } 1-6 \mathrm{~m} \text {. }\end{array}$ \\
\hline $\begin{array}{l}1000 \\
\mathrm{MHz}\end{array}$ & $\begin{array}{l}\text { The } 1000 \mathrm{MHz} \text { antenna used for high quality radar measurements. It is commonly used for concrete, reinforcement studies } \\
\text { and for road mapping and quality assurance. Lower limit of object target size is } 0.01 \mathrm{~m} \text {. Approximate depth range is } 0.05-2 \\
\text { m. Approximate max. penetration depth is } 0.5-4 \mathrm{~m} \text {. }\end{array}$ \\
\hline
\end{tabular}

\section{Experimental Materials Details}

Details used in the experimental work illustrated as follow:

\subsection{Radar Measurements}

The penetration depth of GPR is determined by antenna frequency and the electrical conductivity of the earthen materials being profiled (Daniels, 2004). For higher accuracy site requirements, $1000 \mathrm{MHz}$ RAMAC GPR CU-II was used in cooperation with the Ministry of Science and Technology/ Department of Communications and Space.

\subsection{Concrete Samples}

In this study, six simply supported slab specimens were cast. All slabs were of same dimensions of 600 $\mathrm{mm}$ width, $1000 \mathrm{~mm}$ length and $80 \mathrm{~mm}$ thickness. Two slab specimens were reinforced with bottom steel bars of size $4 \mathrm{~mm}$ with $55 \mathrm{~mm}$ spacing in both directions. Two slab specimens were reinforced with bottom steel bars of size $4 \mathrm{~mm}$ with $85 \mathrm{~mm}$ spacing in both directions. And finally two non-reinforced concrete slabs, slab 3 was mixed and vibrated to get a homogeneous texture, while slab 4 was not in intension to create artificial voids. All the experiments were conducted at room temperature in Constructions Laboratory at the University Of Technology. 


\subsection{Load Specifications}

The control slab dimensions and reinforcement details were governed by using the well-known method of yield line. It was supposed that slabs were resting on simple supports from all sides. All slabs would be subjected to a $200 \mathrm{~mm}$ square patch load centered at mid span. Slabs were subjected to $40 \%$ of their failure load.

\section{Experimental Results and Discussion}

Results obtained from experimental work are shown and discussed as follows:

\subsection{General Data Processing}

Individual files were combined into a solid model to produce the 3D imaging using the Easy 3D (v.1.2.1) software.

\subsection{Reinforcement Bars and Condition Assessment}

Three dimensional imaging were achieved. The three dimensional grid radargrams were done as follows: in horizontal lines and for $\mathrm{x}-\mathrm{y}$ directions, $\mathrm{z}$ amplified, Figures (2) to (7) shows the 3D imaging of the slabs post-loading. Filters applied in easy 3D are: average, DC adjustment and HFIR.

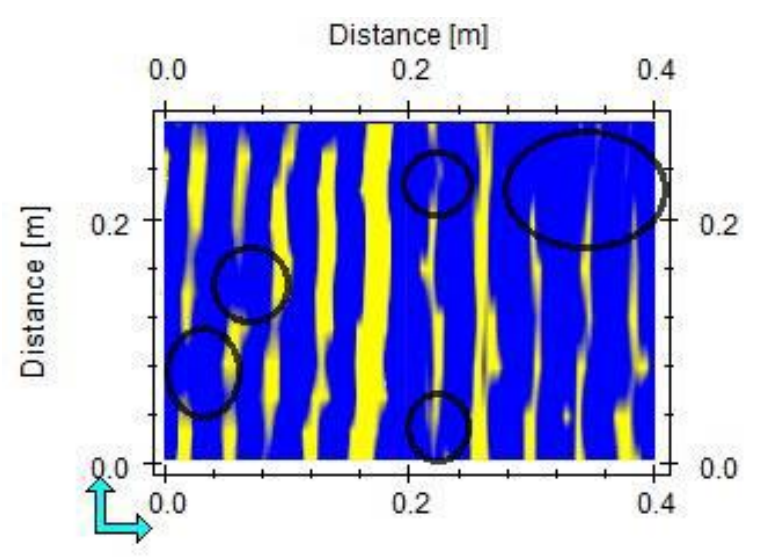

Fig.2 Three-dimensional imaging for slab $1 \mathrm{~W}$

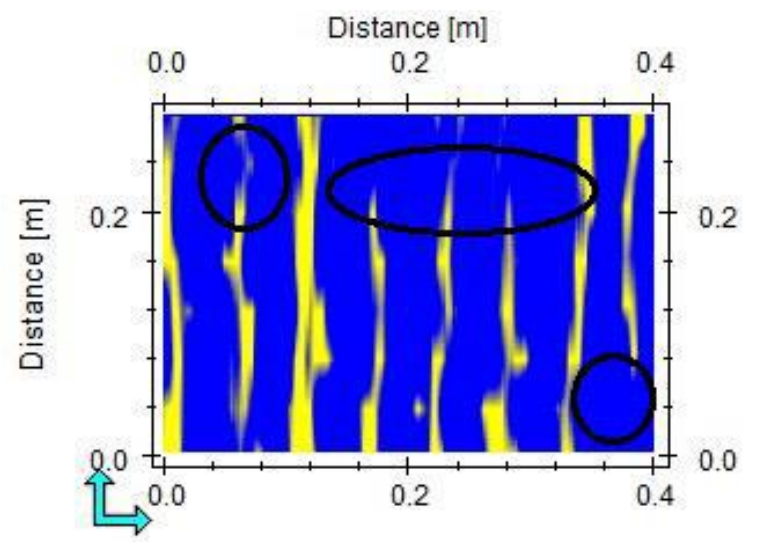

Fig.3 Three-dimensional imaging for slab 1W/0

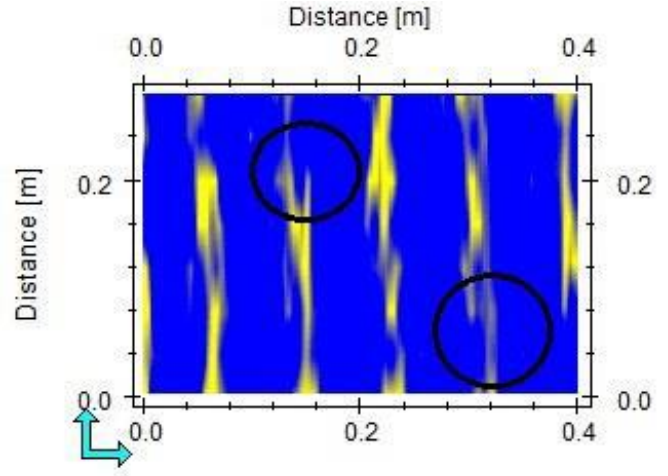

Fig.4 Three-dimensional imaging for slab $2 \mathrm{~W}$

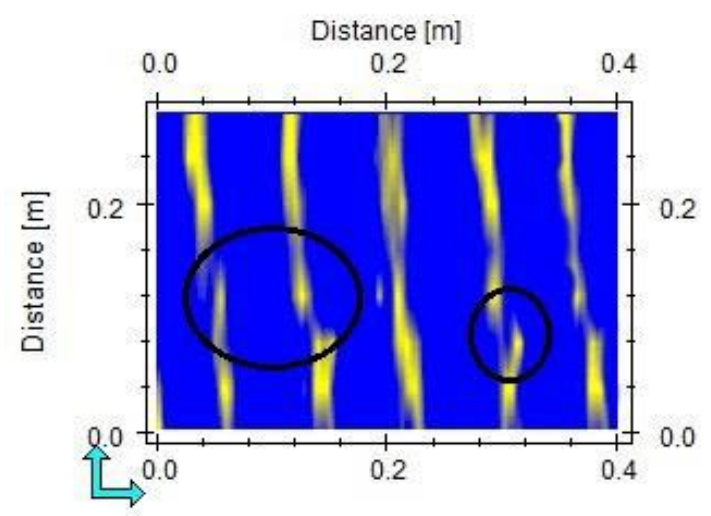

Fig.5 Three-dimensional imaging for slab $2 \mathrm{~W} / 0$

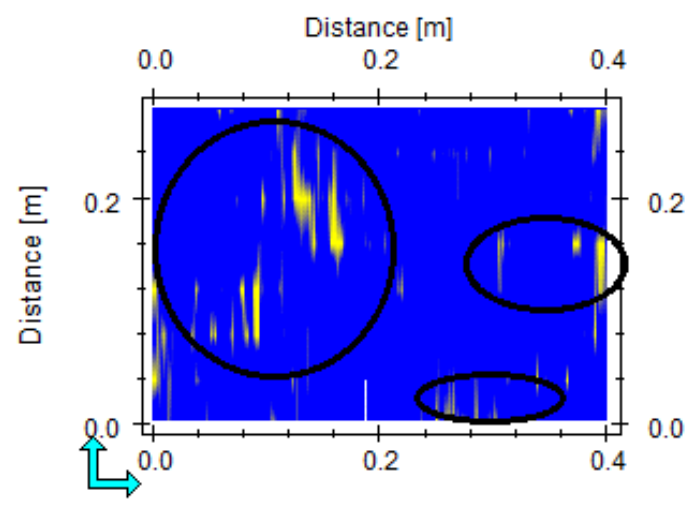

Fig.6 Three-Dimensional Imaging for Slab 3

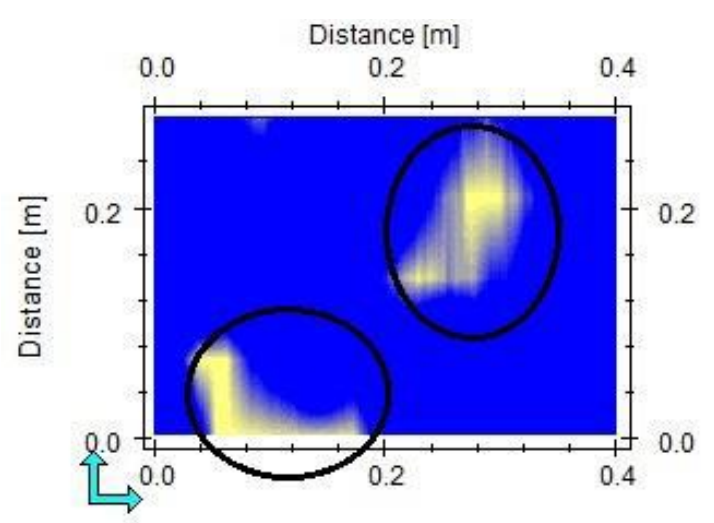

Fig.7 Three-dimensional imaging for slab 4 
It's is so obvious that after applying $40 \%$ percentage of the failure load, that the radargram images of the slabs suffers from low resolution for reinforcement and some cracks are clearly appeared compared by the radargrams of the same slabs before applying the load. The data was lost due to initial cracks and the image suffered from attenuation. This accrued by the reflected waves by the closets cracks to the surface, the initial cracks were on a layer above the reinforcement steel bars, therefor the radargram showed fake gaps in the reinforcement steel bars. The quality of the image suffered too leading to different rebar thickness.

Slab 3 in Figure (6) represents the homogeneous slab texture after enduring the $40 \%$ of the failure load. The initial cracks circled in the figure can be obviously seen, but this can be a high layer in the slab and other cracks can be hidden underneath that layer in a deeper thickness within the same slab.

Slab 4 in Figure (7) shows a different crack position compared to the same exact slab before applying their $40 \%$ of their failure load. Even though one big void has almost the same place, there was a distortion in the positions. Bigger void indicates a mix of the artificial void with the initial cracks.

\section{Conclusions and Future Work}

From the intensive implementation of the GPR technique for six different slabs, the following conclusions are achieved and introduced as follows:

1) Data acquisition may get incoherence by reflections of steel reinforcement bars, this leads to forfeit some important data (ex. Gaps of length 3 $\mathrm{cm}$ and smaller).

2) The results of this study indicate that ground penetrating radar techniques can be employed in some areas to quickly and accurately determine the damage in concrete structures.

3) Finally, the extent and severity of the fatigue cracking was possible to be monitored. In addition, the technique was assistive in determining the failure caused by loading reflected by radargrams.
In light of the current study, the following suggestion can be recommended for future studies:

1) Using multi-channeled GPR with higher frequency (e.g. $1.6 \mathrm{GHz}$ ) to promote more accurate damage monitoring data using Surfer or Tera plot softwares.

2) Using two reinforcement layers to examine the ability of detecting accurate data for each reinforcement layer and locate which layer is damaged

\section{References}

J. J. Daniels (1996), Surface Penetrating Radar. Radar sonar navigation and avionics series, The Institution of Electrical Engineers, London, UK.

Buan Sen Tan (2002), TEM horn antennas for landmine detection applications. Thesis report, Queensland University.

Benson R. C., R. A. Glaccum, and M. R. Noel (1983), Geophysical techniques for sensing buried wastes and waste migration. National Water Well Association.

http://www.hanford.gov/dqo/project/level5/burwm/burw m.pdf.

Imse J.P. and E.N. Levine (1985), Conventional and state-ofthe-art geophysical techniques for fracture detection. Proceedings Second Annual Eastern Groundwater Conference, pages 261-278.

Wright D.L., Olhoeft G.R., and Watts R.D. (1984), Groundpenetrating radar studies on cape cod, in conference on surface and borehole geophysical methods in ground water investigations. Proceedings: U.S. Environmental Protection Agency and National Water Well Association, San Antonio, $T X$, pages 666-680.

Yuejian Cao, Shongtao Dai, Joseph F. Labuz, John Pantelis (2007), Implementation of Ground Penetrating Radar ,Local Road Research Board Minnesota Department of Transportation.

Griffin, S. and Pippett, T. (2002), Ground Penetrating Radar", Geophysical and Remote Sensing Methods for Regolith Exploration, report 144, pp 80-89.

Easy Locator Operator's Manual v. 2.6, from http/www.malags.com

Daniels, D. J., (2004), "Ground Penetrating Radar, 2nd Edition", the Institute of Electrical Engineers, London, United Kingdom. 